\title{
A STUDY ON THE AETIOLOGICAL PROFILE OF PAIN AROUND SHOULDER AMONG PATIENTS ATTENDING PHYSICAL MEDICINE AND REHABILITATION DEPARTMENT OF A TERTIARY CARE CENTRE
}

\author{
Roy Rama Chandran'1, Charvakan Suthan², Santhosh Kothirappallil Raghavan'3 , Mitu Chirakkalthazhath Sankar", Dhanya Raj5 \\ ${ }^{1}$ Assistant Professor, Department of Physical Medicine and Rehabilitation, Government TD Medical College, Alappuzha. \\ ${ }^{2}$ Assistant Professor, Department of Physical Medicine and Rehabilitation, Government TD Medical College, Alappuzha. \\ ${ }^{3}$ Associate Professor and HOD, Department of Physical Medicine and Rehabilitation, Government TD Medical College, Alappuzha. \\ ${ }^{4}$ Senior Resident, Department of Physical Medicine and Rehabilitation, Government TD Medical College, Alappuzha. \\ ${ }^{5}$ Lecturer, Department of Physical Medicine and Rehabilitation, Government TD Medical College, Alappuzha.
}

\section{ABSTRACT}

\section{BACKGROUND}

Pain around the shoulder is one of the most common regional musculoskeletal conditions seeking medical advice. It has a lifetime prevalence of up to $70 \%$ and this seems to be increasing in incidence. The diagnosis of these disorders is based primarily upon results of specific clinical tests. There are not many studies regarding its aetiological profile.

The aim of this study is to assess the proportion of various disorders causing pain in and around the shoulder joint in patients reporting to the Physical Medicine and Rehabilitation Department of a tertiary care hospital in Kerala.

\section{MATERIALS AND METHODS}

This study was carried out in the Outpatient Department of Physical Medicine and Rehabilitation, Government TD Medical College, Alappuzha, during a period of one year from April 2016 - March 2017 to assess the aetiological profile of various disorders causing pain around the shoulder joint. This was a descriptive study conducted by evaluating the final diagnosis from the OP records of patients who were fully evaluated in the Shoulder Pain Clinic, which is functioning in the department.

\section{RESULTS}

Age of patients ranged between 15 to 85 years (mean age 48 years). A predominance of females was observed (Male-Female ratio: 1: 1.84). The commonest causes of pain around the shoulder joint were myofascial pain (38.2\%) followed by rotator cuff disease (29.7\%), adhesive capsulitis (19.1\%). Other causes were C5 radiculopathy (3.8\%), brachial plexopathy (1.7\%) and GH arthritis (1\%); 2 cases of acromioclavicular joint arthritis and one case of malignancy (multiple myeloma) were also diagnosed. Myofascial pain was more seen among younger age group; $96.5 \%$ with myofascial pain were in the below 50 years of age category. Rotator cuff disease and adhesive capsulitis were seen more common in the middle and older age group. $70 \%$ of rotator cuff disease and $75 \%$ of patients with adhesive capsulitis were in the $>50$ years of age category.

\section{CONCLUSION}

Myofascial pain, rotator cuff disease and adhesive capsulitis were three most common diagnoses reporting to our centre with pain around shoulder. Myofascial pain is more common in females (P value of 0.00 ) and rotator cuff injury is more in males (P value of 0.00). Adhesive capsulitis was seen almost similar in both with a slight male predominance.

\section{KEYWORDS}

Aetiological Profile, Pain around Shoulder Joint, Adhesive Capsulitis, Myofascial Pain, Rotator Cuff Disease.

HOW TO CITE THIS ARTICLE: Chandran RR, Suthan C, Raghavan SK, et al. A study on the aetiological profile of pain around shoulder among patients attending physical medicine and rehabilitation department of a tertiary care centre. J. Evolution Med. Dent. Sci. 2017;6(46):3595-3599, DOI: 10.14260/Jemds/2017/775

\section{BACKGROUND}

Shoulder pain is the third most common cause of musculoskeletal disorder after Low Back Pain (LBP) and cervical pain, which presents to general practice. ${ }^{1}$ Pain of shoulder and around it has large healthcare costs and a major impact on the health of affected individuals including absence

Financial or Other, Competing Interest: None.

Submission 02-05-2017, Peer Review 27-05-2017,

Acceptance 02-06-2017, Published 08-06-2017.

Corresponding Author:

Dr. Roy Rama Chandran,

Assistant Professor,

Department of Physical Medicine and Rehabilitation,

Government TD Medical College,

Vandanam, Alappuzha-688005, Kerala.

E-mail: royramachandran@gmail.com

DOI: $10.14260 /$ jemds $/ 2017 / 775$

(c) $($ ) $($ ) from work and disability. Shoulder complaints may have an unfavourable outcome with only about $50 \%$ of all new episodes of shoulder complaints presenting in medical practice showing a complete recovery within 6 months. ${ }^{2,3}$ After 1 year, this proportion increases to $60 \%{ }^{3}$

One of the largest and earliest population-based studies that used a self-administered questionnaire was conducted by Hasvold et al. ${ }^{4}$ The aim of the study was to determine the prevalence of neck or shoulder pain as part of a general health screening procedure in Norway, and also the direct consequences of these complaints. The sample size was 29,026 with a $75 \%$ response rate. The prevalence of shoulder pain was estimated to be $15.4 \%$ in men and $24.9 \%$ in women who reported weekly episodes of pain. The study also reported a significant increase in pain prevalence or severity with age most significantly in the 50 - 56 years' age bracket. The study determined that as many as $30 \%$ of participants 
from both sexes reported being significantly disadvantaged at work and unable to perform simple tasks. Similar prevalence estimations of shoulder pain were also determined by Pope et $\mathrm{al}^{5}$ with the total level of suffering in the community from shoulder pain to be as great as $20 \%$ of the population.

Shoulder pain may originate from multiple anatomical structures in and around the shoulder. This explains why shoulder pain and dysfunction occur in many musculoskeletal disorders and other diseases. These include both noninflammatory soft tissue rheumatic conditions around the shoulder joint and inflammatory conditions. Since soft tissue plays an important role in the stability and function of the shoulder, it is important to consider the multifactorial nature of shoulder complaints with interplay between disease; predisposition and mechanical factors. ${ }^{6}$ Defining shoulder pain in terms of separate anatomical diagnoses requires detailed physical examination. ${ }^{7}$

The classification of a case of 'shoulder pain' has been approached in various ways in studies of its occurrence. Many studies have asked directly about the presence of pain in and around the shoulder.8,9 This relies however on the respondents' perceptions as to the anatomical origin of their symptoms. Pain arising from structures around the shoulder complex are often felt in a wider area, for example the neck, upper arm or upper trunk ${ }^{10}$ and thus may be undetected with such a 'self-perceived' definition. Alternatively, pain drawings or manikins have been used. ${ }^{11}$ These require the respondent to indicate the presence or absence of symptoms on a line drawing of the body and have the advantage that they can be independently classified. Referred symptoms originating outside the shoulder complex, however, might artificially inflate prevalence estimates based on such a definition.

A number of other community-based studies have been cited in the literature with sound methodological quality. These include a study from Finland that demonstrated a shoulder pain prevalence of $17 \%$ over a 12 -month period in a mixed population of adults from the age of $40-64$ years. The definition of shoulder pain used in this study included ache or stiffness in the shoulder or upper arm and a difficulty in movement. 9

The prevalence of shoulder pain has also been investigated in a community-based rheumatology practice. ${ }^{12}$ Eleven thousand patients from a large general practice were referred for assessment over a nine-month period. Diagnosis was based on an accurate history with a directed examination. The most common source of pain in the shoulder was found to be soft tissue lesions (81\%), of which the bulk were lesions of the rotator cuff (65\%), periscapular soft tissue (11\%), acromioclavicular joint pain (10\%) and cervical referred pain (5\%).

The studies from India showed that the shoulder pain was one of the major work related musculoskeletal complaint. ${ }^{13,14,15}$ The prevalence of shoulder pain in India has been reported to be $2 \%$ among urban and $7.4 \%$ among rural population. ${ }^{16,17}$

In this study, we intended to evaluate the epidemiology of pain in and around the shoulder joint complex which included articular pain like adhesive capsulitis, acromioclavicular joint arthritis, sternoclavicular joint arthritis and soft tissue rheumatic symptoms around shoulder joint complex like regional myofascial pain around shoulder joint complex, rotator cuff disease and bursitis, neurological conditions which presented as pain around the shoulder joint complex like C5 radiculopathy and plexitis, and miscellaneous conditions like malignancy which presented with pain around shoulder. This was a hospital-based study carried out in the Outpatient Department of Physical Medicine and Rehabilitation of a tertiary care centre during a period of one year to assess the proportion of various disorders causing pain around the shoulder joint. This was a descriptive study done with secondary data from OP records, which was conducted in the shoulder pain clinic functioning in the department.

\section{Rotator Cuff Disease}

The prevalence of a rotator cuff tear was considerably greater in males than in females within the ages of 50 - 60 years old; within the ages of $70-80$ years old there was not much difference in prevalence. ${ }^{18}$ A study by Minagawa $\mathrm{H}$ et al showed that the prevalence of a rotator cuff tear in the general population is $22.1 \% .^{18}$ Yamamoto et al performed a medical examination on 683 people to determine the prevalence of a rotator cuff disease among general population. They found that rotator cuff tears were present in $20.7 \% .{ }^{19}$

In an autopsy study of rotator cuff diseases, the incidence of partial tears was found in $28 \%$, and of complete rupture $30 \%$. Frequently, tears occurred bilaterally and it increased with age. The frequency was also higher among females. ${ }^{20}$

\section{Adhesive Capsulitis (AC)}

Adhesive capsulitis usually affects patients aged $40-70$ years. The incidence of AC is not precisely known; however, it is estimated that $2 \%$ of people develop the disease over their lifetime. Males tend to be affected less frequently than females, and there is no predilection for race. In general, bilateral shoulder involvement is rarely simultaneous and instead occurs sequentially. The incidence of adhesive capsulitis is approximately 3 percent in the general population. ${ }^{21,22}$ It is rare in children ${ }^{23}$ and peaks between 40 and 70 years of age. ${ }^{22}$ Women are more often affected than men, but there is no known genetic or racial predilection.

\section{Myofascial Pain (MFP)}

Myofascial trigger points are quite common, especially around shoulder and cervical musculature, and are most often found in patients 31 to 50 years of age with a greater incidence in women than men.

Studies indicate that myofascial pain syndrome is a far more common cause of both chronic and acute musculoskeletal pain than is generally recognised. ${ }^{24}$ It apparently is the most common cause of the pain that brings patients to chronic pain treatment centres. A few controlled studies have been published on the prevalence of this condition. There appears to be a female predominance with estimates varying between 1.5: 1 and 3: 1 . Among 283 consecutive admissions to a comprehensive pain clinic, $85 \%$ were assigned a primary organic diagnosis of myofascial syndrome. ${ }^{25}$ Among 296 patients referred to a dental clinic for chronic head and neck pain of at least 6 months' duration, the primary diagnosis was myofascial pain in $55.4 \%$ of cases. ${ }^{26}$ Acute myofascial pain is also common in general medical practice. Among 61 consecutive consultation or 
followup patients in an internal medicine group practice, $10 \%$ of all patients and $31 \%$ of those presenting with a pain complaint had myofascial trigger points identified as being primarily responsible for their symptoms. ${ }^{27}$

\section{Acute Brachial Plexus Neuritis}

Most cases of acute brachial plexus neuritis occur between 20 and 60 years of age; however, cases have been reported in all age groups. A male predominance is reported with a male-tofemale ratio ranging from 2: 1 to $11.5: 1 .^{28,29,30}$ The annual incidence has been estimated as 1.64 cases per 100,000 persons, but this figure is probably low because many cases may be misdiagnosed or the symptoms are mild and clinically unrecognised. ${ }^{31}$

\section{Cervical Radiculopathy}

An epidemiologic survey showed the annual age-adjusted incidence of radiculopathy to be 83 per 100,000 persons. Persons reporting radiculopathy were between 13 and 91 years of age, and men were affected slightly more than women. ${ }^{32}$

\section{Acromioclavicular Joint Arthritis}

Osteoarthritis is the most common cause of pain in the AC joint and can arise from a number of potential causes, including degenerative, posttraumatic, septic and inflammatory processes. In a study assessing age-related changes of the AC joint, De Palma et $\mathrm{al}^{33}$ found that a majority demonstrated degenerative changes by the fourth decade of life. But the true prevalence of AC arthritis is largely unknown because of variability in the criteria used to define arthritis in the literature. ${ }^{34}$

\section{Aims and Objectives}

The aim of this study is to assess the proportion of various disorders causing pain around the shoulder joint in patients reporting to the Physical Medicine and Rehabilitation Department of a tertiary care hospital in Kerala.

There have been only few studies done in the past reporting the aetiological profile of pain around the shoulder. Most of them were done in primary or secondary care centres by different investigators in different hospitals and in some the data obtained from their respective clinics were simply clubbed and reported.3,5,6 The results in these studies vary much due to the fact that they were diagnosed by primary care physicians and also because the disease definition itself in certain cases is ambiguous.

\section{MATERIALS AND METHODS}

The study entitled- "A study on the aetiological profile of pain around shoulder among patients attending Physical Medicine and Rehabilitation Department of a tertiary care centre" was a hospital-based study carried out in the Outpatient Department of Physical Medicine and Rehabilitation, Government TD Medical College, Alappuzha, during a period of one year from April 2016 - March 2017 to assess the proportion of various disorders causing pain around the shoulder joint. This was a descriptive study on secondary data of hospital records conducted by evaluating the final diagnosis from the OP records of patients who were evaluated in the Shoulder pain clinic functioning in the department. The final diagnosis had been entered in the OP records after proper clinical evaluation and investigations by an experienced Physiatrist who was in charge of the Shoulder pain clinic.

In this study, we tried to evaluate the epidemiology of pain in and around the shoulder joint complex which included arthritis of joints in the shoulder joint complex, soft tissue rheumatic symptoms around shoulder joint complex, neurological conditions which presented with pain around the shoulder joint complex and miscellaneous conditions like malignancy and referred pain which presented as pain around shoulder. We excluded regional pain syndromes around neck and pain which radiate from neck to arm.

\section{Statistical Analysis}

A total of 293 patients who attended the Shoulder pain clinic during the study period were included in the study. All the data were entered in Microsoft Excel sheet, rechecked and analysed with SPSS 16 statistical software. For categorical variables chi-square test and for continuous variables descriptive analysis was used in statistical analysis.

\section{RESULTS}

Age of patients ranged between 15 - 85 years (mean age 48 years); 190 of them were females (64.8\%) and 103 were males (35.2\%). Predominantly, right-sided symptoms were seen in $76 \%$.

The commonest causes of pain around the shoulder joint are given in Table 1 . They are myofascial pain (38.2\%) followed by rotator cuff disease $(29.7 \%)$, adhesive capsulitis (19.1\%), C5 radiculopathy (3.8\%), brachial plexopathy (1.7\%) and GH arthritis (1\%); 2 cases of acromioclavicular joint arthritis and one case of malignancy (multiple myeloma) were also diagnosed (Table 1).

Disease wise myofascial pain was more seen in females and rotator cuff disease was more in males. Adhesive capsulitis was seen almost similar in both with a slight male predominance (Males 22.3\% and Females 17.4\%).

Gender wise, in females the main cause of pain around shoulder was myofascial pain $(54.7 \%)$ followed by rotator cuff disease (18.4\%) and adhesive capsulitis (17.4\%) and the difference was statistically significant ( $\mathrm{P}$ value of 0.00 ) in case of myofascial pain (Table 1 and Chart 1). While in males, the pain was mainly due to rotator cuff disease $(50 \%)$ followed by adhesive capsulitis $(22.3 \%)$ and myofascial pain $(7.8 \%)$. The difference was statistically significant (P value of 0.00 ) in rotator cuff disease (Table 1 and Chart 1). Myofascial pain was the cause of pain around the shoulder in more than half $(54.7 \%)$ of the female patients in this study. In half of males, the main cause was rotator cuff disease.

Age wise aetiological distribution is as follows. Myofascial pain was more among younger age group; 96.5\% with myofascial pain were in the below 50 years of age category. Rotator cuff disease was more common in the middle and older age group; $70 \%$ of patients with rotator cuff disease and $75 \%$ of them with adhesive capsulitis were in the $>50$ years of age category (Table 2 and Chart 2). 


\begin{tabular}{|c|c|c|c|c|}
\hline Diagnosis & $\begin{array}{c}\text { Total } \\
(\mathbf{n = 2 9 3 )}\end{array}$ & $\begin{array}{c}\text { Females } \\
(\mathbf{n = 1 9 0})\end{array}$ & $\begin{array}{c}\text { Males } \\
(\mathbf{n}=\mathbf{1 0 3})\end{array}$ & $\begin{array}{c}\text { P } \\
\text { value }\end{array}$ \\
\hline MFP & $112(38.2 \%)$ & $104(54.7 \%)$ & $8(7.8 \%)$ & 0.00 \\
\hline RCD & $87(29.7 \%)$ & $35(18.4 \%)$ & $52(50 \%)$ & 0.00 \\
\hline AC & $56(19.1 \%)$ & $33(17.4)$ & $23(22.3 \%)$ & 0.190 \\
\hline C5 Rad & $11(3.8 \%)$ & $6(3 \%)$ & $5(4.8 \%)$ & 0.333 \\
\hline $\begin{array}{c}\text { Bra. } \\
\text { Plexopathy }\end{array}$ & $5(1.7 \%)$ & $0(0 \%)$ & $5(4.8 \%)$ & 0.005 \\
\hline GH Arthritis & $3(1 \%)$ & $1(0.5 \%)$ & $2(1.9 \%)$ & 0.283 \\
\hline ACJ Arthritis & $2(0.7 \%)$ & $1(0.5 \%)$ & $1(0.9 \%)$ & 0.583 \\
\hline Malignancy & $1(.34 \%)$ & 0 & $1(0.9 \%)$ & 0.352 \\
\hline \multicolumn{5}{|c|}{ Table 1. Association of Diagnosis with Gender } \\
\hline
\end{tabular}

MFP: Myofascial Pain, RCD: Rotator Cuff Disease, AC: Adhesive Capsulitis; C5 Rad: C5 Radiculopathy, Bra. Plexopathy: Bracheal Plexopathy; GH OA: Glenohumeral Arthritis; ACJ Arthritis: Acromioclavicular Joint Arthritis.

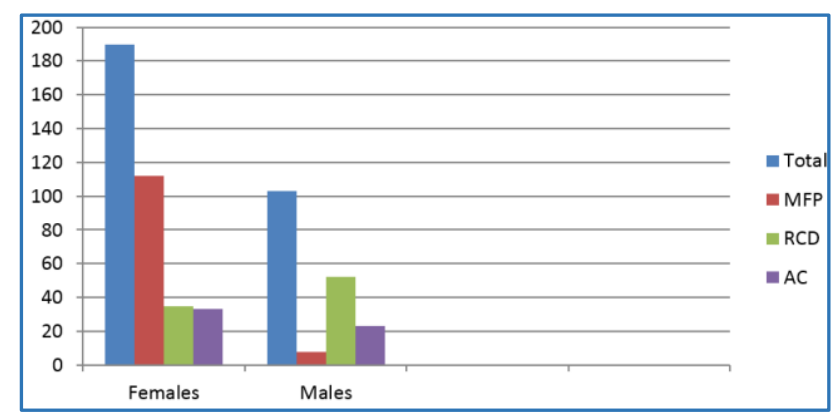

Chart 1. Association of Diagnosis with Gender

MFP: Myofascial Pain, RCD: Rotator Cuff Disease, AC: Adhesive Capsulitis.

\begin{tabular}{|c|c|c|c|}
\hline $\begin{array}{c}\text { Age } \\
\text { Group }\end{array}$ & $\begin{array}{c}\text { MFP } \\
\text { n (\%) }\end{array}$ & $\begin{array}{c}\text { RCD } \\
\mathbf{n}(\mathbf{6})\end{array}$ & $\begin{array}{c}\text { AC } \\
\mathbf{n}(\mathbf{6})\end{array}$ \\
\hline$<30$ Years & $29(25.9 \%)$ & $4(4.6 \%)$ & $1(1.8 \%)$ \\
\hline 31 - 40 Years & $47(42 \%)$ & $6(6.9 \%)$ & $0(0 \%)$ \\
\hline 41 - 50 Years & $32(28.6 \%)$ & $20(23 \%)$ & $13(23.2 \%)$ \\
\hline 51 - 60 Years & $4(3.6 \%)$ & $31(35.6 \%)$ & $18(32.1 \%)$ \\
\hline 61 - 70 Years & $0(0 \%)$ & $21(24.1 \%)$ & $19(33.9 \%)$ \\
\hline$>71$ Years & $0(0 \%)$ & $5(5.7 \%)$ & $5(8.9 \%)$ \\
\hline \multicolumn{4}{|c|}{ Table 2. Association of Diagnosis with Age } \\
\hline
\end{tabular}

MFP: Myofascial Pain, RCD: Rotator Cuff Disease, AC: Adhesive Capsulitis.

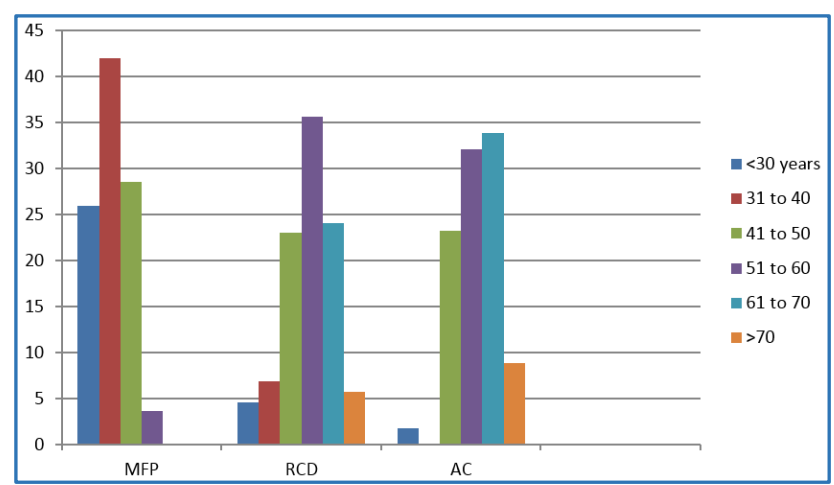

Chart 2. Association of Diagnosis with Age

MFP: Myofascial Pain, RCD: Rotator Cuff Disease, AC: Adhesive Capsulitis.

\section{DISCUSSION}

Pain around the shoulder joint is a common presenting complaint among patients attending the Department of Physical Medicine and Rehabilitation (PM and R). But there have been only few studies done in past reporting the aetiological profile of pain around the shoulder. Most of them were conducted in the primary or secondary care centres and the results in these studies vary much due to fact that they were diagnosed by primary care physicians. Very few studies were conducted in tertiary care units, where the evaluation is mainly by specialists. No similar studies were conducted in PM and R Departments in India. The aim of this study is to assess the proportion of various disorders causing pain around the shoulder joint in patients reporting to the PM and $\mathrm{R}$ Department of a tertiary care hospital.

In our study, it was found that the commonest cause of pain around the shoulder was due to myofascial pain and this was more frequently seen in females and mainly in persons < 50 years of age. As the studies on the prevalence of myofascial pain around the shoulder were rare, we tried to see any comparison if any exists between the results of this study with studies on the incidence of myofascial pain in general population. Many population studies including the one by Simons DG et $\mathrm{al}^{24}$ indicated that myofascial pain syndrome is a far more common cause of both chronic and acute musculoskeletal pain than is generally recognised. There appears to be female predominance with estimates varying between 1.5: 1 and 3: 1 . Skootsky SA et al ${ }^{25}$ found that majority of patients who got admitted to a comprehensive pain clinic had a primary organic diagnosis of myofascial syndrome. ${ }^{25}$ Among 61 consecutive consultation or followup, patients in an Internal Medicine Group practice $10 \%$ of all patients and $31 \%$ of those presenting with a pain complaint had myofascial trigger points identified as being primarily responsible for their symptoms. ${ }^{27}$

After myofascial pain, the other common causes were rotator cuff disease and adhesive capsulitis. They were found mainly in patients older than 50 years of age and more in males.

Our results are very close to the findings of the studies by Minagawa $\mathrm{H}$ et $\mathrm{al}^{18}$ on rotator cuff diseases. The study on adhesive capsulitis by Bridgman JF et $\mathrm{al}^{22}$ showed that its incidence peaks between 40 and 70 years of age, but with a female predominance. In our study, adhesive capsulitis was seen almost similar in both with a slight male predominance. (Males 22.3\% and females $17.4 \%$ ).

\section{CONCLUSION}

1. This is the first report on aetiological profile of the symptom of pain around shoulder reporting to Physical Medicine and Rehabilitation Department of a Tertiary Care Centre in India, especially assessing the age and gender related proportion.

2. The common causes of pain around the shoulder joint were myofascial pain $(38.2 \%)$ followed by rotator cuff disease (29.7\%) and adhesive capsulitis (19.1\%).

3. Myofascial pain was the commonest cause of pain around shoulder in females. It was the predominant cause of pain in $54.7 \%$ of them.

4. In males, the main cause of pain around shoulder was rotator cuff disease $(50 \%)$.

5. Adhesive capsulitis was slightly more in males, but not statistically significant. 
6. Myofascial pain was seen more in young persons, and the occurrence of rotator cuff disease and adhesive capsulitis were more seen after 50 years.

\section{Limitations of the Study}

It was a hospital-based study conducted in a tertiary care centre, and hence may not be representative of general population.

\section{ACKNOWLEDGEMENT}

Dr. Binny K, MD, for helping in statistical analysis.

\section{REFERENCES}

[1] McCormick A, Fleming D, Charlton J, et al. Morbidity statistics from general practice: fourth national study 1991-92. London: HMSO 1996:55.

[2] Croft P, Pope D, Silman A. The clinical course of shoulder pain: prospective cohort study in primary care. Primary Care Rheumatology Society Shoulder Study Group. BMJ 1996;313(7057):601-2.

[3] van der Windt DA, Koes BW, Boeke AJ, et al. Shoulder disorders in general practice: prognostic indicators of outcome. Br J Gen Pract 1996;46(410):519-23.

[4] Hasvold T, Johnsen R. Headache and neck or shoulder pain - frequent and disabling complaints in the general population. Scandinavian Journal of Primary Health Care 1993;11(3):219-24.

[5] Pope D, Croft P, Pritchard C, et al. Prevalence of shoulder pain in the community: the influence of case definition. Ann Rheum Dis 1997;56(5):308-12.

[6] Bjelle A. Epidemiology of shoulder problems. Bailliere's Clinical Rheumatology 1989;3(3):437-51.

[7] Cyriax J. Textbook of orthopedic medicine. Diagnosis of soft tissue lesions. 1.6 $6^{\text {th }}$ edn. London: Bailliere Tindall 1976

[8] Cunningham LS, Kelsey JL. Epidemiology of musculoskeletal impairments and associated disability. Am J Public Health 1984;74(6):574-9.

[9] Takala J, Sievers K, Klaukka T. Rheumatic symptoms in the middle-aged population in southwestern Finland. Scand J Rheumatol 1982;47:15-29.

[10] Spangfort E. Clinical aspects of neck-and-shoulder pain. Scand J Rehab Med Suppl 1995;32:43-6.

[11] Andersson HI, Ejlertsson G, Leden I, et al. Chronic pain in a geographically defined general population: studies of differences in age, gender, social class and pain localisation. Clin J Pain 1993;9(3):174-82.

[12] Vecchio P. Kavanagh R, Hazleman BL, et al. Shoulder pain in a community-based rheumatology clinic. British Journal of Rheumatology 1995;34(5):440-2.

[13] Kumar VK, Kumar SP, Baliga MR. Prevalence of workrelated musculoskeletal complaints among dentists in India: a national cross-sectional survey. Indian J Dent Res 2013;24(4):428-38.

[14] Sankar SG, Reddy PV, Reddy BR, et al. The prevalence of work-related musculoskeletal disorders among Indian orthodontists. J Indian Orthop Soc 2012;46(4):264-8.

[15] Vijay SA. Work-related musculoskeletal health disorders among the information technology professionals in India: a prevalence study. Int J Mgmt Res Bus Strat 2013;2(2):118-28.
[16] Chopra A, Saluja M, Patil J, et al. Pain and disability, perceptions and beliefs of a rural Indian population: a WHO-ILAR COPCORD study. WHO-International League of Associations for Rheumatology. Community Oriented Program for Control of Rheumatic Diseases. J Rheumatol 2002;29(3):614-21.

[17] Joshi VL, Chopra A. Is There an urban-rural divide? Population surveys of rheumatic musculoskeletal disorders in the Pune region of India using the COPCORD Bhigwan model. J Rheumatol 2009;36 (3):614-22.

[18] Minagawa H, Yamamoto N, Abe H, et al. Prevalence of symptomatic and asymptomatic rotator cuff tears in the general population: from mass-screening in one village. Journal of Orthopaedic 2013;10(1):8-12.

[19] Yamamoto A, Takagishi K, Osawa T, et al. Prevalence and risk factors of a rotator cuff tear in the general population. J Shoulder Elbow Surg 2010;19(1):116-20.

[20] Jerosch J, Müller T, Castro WH. The incidence of rotator cuff rupture. An anatomic study. Acta Orthop Belg 1991;57(2):124-9.

[21] Tighe CB, Oakley WS. The prevalence of a diabetic condition and adhesive capsulitis of the shoulder. South Med J 2008;101(6):591-5.

[22] Bridgman JF. Periarthritis of the shoulder and diabetes mellitus. Ann Rheum Dis 1972;31(1):69-71.

[23] Modesto C, Crespo E, Villas C, et al. Adhesive capsulitis. Is it possible in childhood? Scand J Rheumatol 1995;24(4):255-6.

[24] Simons DG. Myofascial pain syndromes: where are we? Where are we going? Arch Phys Med Rehabil 1988;69(3 Pt 1):207-12.

[25] Skootsky SA, Jaeger B, Oye RK. Prevalence of myofascial pain in general internal medicine practice. West J Med 1989;151(2):157-60.

[26] Fricton JR, Kroening R, Haley D, et al. Myofascial pain syndrome of the head and neck: a review of clinical characteristics of 164 patients. Oral Surg Oral Med Oral Pathol 1985;60(6):615-23.

[27] Simons DG. Symptomatology and clinical pathophysiology of myofascial pain. Schmerz 1991;5(Suppl 1):S29-37.

[28] Misamore GW, Lehman DE. Parsonage-Turner syndrome (acute brachial neuritis). J Bone Joint Surg Am 1996;78(9):1405-8.

[29] Turner JWA. Acute brachial radiculitis. BMJ 1944;2(4374):592-4.

[30] Turner JW, Parsonage MJ. Neuralgic amyotrophy (paralytic brachial plexus neuritis) with special reference to prognosis. Lancet 1957;270(6988):20912.

[31] Beghi E, Kurland LT, Mulder DW, et al. Brachial plexus neuropathy in the population of Rochester, Minnesota, 1970-1981. Ann Neurol 1985;18(3):320-3.

[32] Radhakrishnan K, Litchy WJ, O'Fallon WM, et al. Epidemiology of cervical radiculopathy. A populationbased study from Rochester, Minnesota, 1976 through 1990. Brain 1994;117(Pt 2):325-35.

[33] DePalma A, Callery G, Bennett GA. Variational anatomy and degenerative lesions of the shoulder joint. Instr Course Lect 1949;6:255-81.

[34] Shaffer BS. Painful conditions of the acromioclavicular joint. J Am Acad Orthop Surg 1999;7(3):176-88. 